\title{
As contribuições da Profa. Erika Cremer à cromatografia gás-sólido
}

\author{
Carol H. Collins \\ Instituto de Química, Universidade Estadual de Campinas - UNICAMP, \\ Cep 13083-970, Campinas, SP, Brasil \\ e-mail:chc@iqm.unicamp.br
}

\section{Resumo}

Na década de 1940, diversos desenvolvimentos aconteceram separadamente na Europa, relacionados às aplicações da cromatografia gás-sólido com o desenvolvimento por eluição. Neste capítulo, serão descritas as contribuições da Profa. Erika Cremer da Universidade de Innsbruck, Áustria, a esta técnica, com destaque aos seus tratamentos teóricos e considerações quantitativas e à instrumentação construída para este fim.

Palavras-chave

História da cromatografia; cromatografia gás-sólido; instrumentação; Profa. Erika Cremer.

\section{The contributions of Prof. Erika Cremer to gas-solid chromatography}

\section{Abstract}

During the 1940's various developments occurred, separately, in Europe, related to applications of gassolid chromatography with elution development. This chapter describes the contributions of Prof. Erika Cremer of the University of Innsbruck, Austria, to this technique, with attention to her theoretical and quantitative treatments and to the instrumentation constructed for these purposes.

Keywords

History of chromatography; gás-solid chromatography; instrumentation; Prof. Erika Cremer. 
Como descritos no capítulo anterior ${ }^{[1]}$, durante o período de 1935 a 1945, vários grupos estabelecidos na Europa iniciaram estudos visando a separação de compostos voláteis utilizando diversos sorventes sólidos e fases móveis gasosas. Por outro lado, devido aos problemas relacionados à segunda guerra mundial, pouca comunicação entre os diversos pesquisadores ocorria e seus resultados não eram divulgados entre os diferentes grupos de pesquisa. Os trabalhos de uma das pessoas que deram início à cromatografia gás-sólido na década de 1940 serão abordados neste capítulo.

Erika Cremer, 1900-1996 (Figura 1), nasceu em Munique, em uma família com tradição de serem cientistas e professores universitários. Sendo assim, foi natural que ela tenha estudado na Universidade de Berlim, obtendo um doutorado (Ph.D.) em físico-química em 1927. Ficou em Berlim, fazendo pesquisas no Instituto de Físico-Química Kaiser Wilheim (Kaiser Wilhelm Institute fur Physikalisches Chemie) durante a década de 1930, realizando também vários estágios fora da Alemanha. Em 1938, defendeu sua livre-docência (habilitation), também na Universidade de Berlim. Em 1940, foi contratada como professora assistente doutora na Universidade de Innsbruck (hoje na Áustria, naquela data sob o controle de Alemanha), sendo que esta vaga foi colocada à sua disposição pela falta de homens qualificados, devido aos requisitos do exército alemão no período da segunda

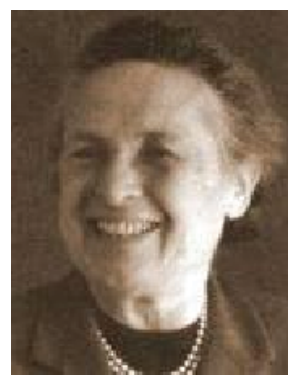

Figura 1 Foto da Profa. Erika Cremer. guerra mundial. Em Innsbruck, encontrou pouco equipamento para continuar seus estudos de adsorção/dessorção de gases em sólidos, para medir os calores de adsorção. Insistindo, ela iniciou estudos sobre a sorção de acetileno na presença de hidrogênio. Logo constatou que precisava um método para verificar a presença de etileno, produzido por uma reação de hidrogênio com acetileno nas condições do seu experimento. Depois de ler o livro de Gerhard Hesse ${ }^{[2]}$ sobre cromatografia líquido-sólido, Cremer pensou que adsorções similares, se acontecessem em gases, permitiriam que ela determinasse o calor de adsorção de ambos os compostos. Um aluno de iniciação científica, A. Kunte, começou a construir um aparelho para medir os calores, após a separação dos dois compostos, utilizando carvão ativado como fase estacionária e hidrogênio como fase móvel. Entretanto os picos não se separaram suficientemente, e os calores não foram distinguíveis com o sistema construído. Os resultados foram descritos na monografia de graduação do Kunte ${ }^{[3]}$. Faltando equipamento apropriado, Cremer escreveu um artigo teórico sobre o assunto, que ela enviou para a revista austríaca Naturwissenschaften. O artigo foi aceito e, em fevereiro de 1945, ela corrigiu as provas. Entretanto, este número da revista nunca foi publicado devido à destruição das máquinas de impressão da editora durante um bombeamento na cidade de Viena. O trabalho foi finalmente publicado em $1976^{[4]}$ como parte de observações históricas da Profa. Cremer sobre suas contribuições à cromatografia ${ }^{[5]}$.

Sem equipamento para continuar seus estudos com gases, durante um certo período, Cremer testou sua teoria com cromatografia líquido-sólido. No fim de 1945, um novo aluno de pós-graduação, Fritz Prior, aceitou o desafio de construir um sistema melhor para fazer a separação de acetileno e etileno. Parte do sis- 
tema de Kunte foi reaproveitada e outros componentes foram emprestados de um colégio onde o aluno dava aulas. $O$ sistema que eles construírem (Figura 2) continha todos os componentes encontrados em um cromatógrafo a gás: fase móvel (hidrogênio), sistema para aplicar a amostra, coluna cromatográfica, recheada com a fase estacionária sólida e termostatisada, e detector, também termostatisado. O detector foi um catarômetro, baseado em um fio de platina, que indicava mudanças na condutividade dos gases ao seu redor, conectado a uma ponte de Wheatstone, com um galvanômetro. As leituras do galvanômetro foram feitas manualmente. $\mathrm{O}$ primeiro cromatograma obtido com este sistema (Figura 3) foi publicado na tese de doutorado do Prior $^{[8]}$, defendida em 1947, no qual indicou que o sistema poderia ser usado para fins qualitativos, fazendo uso do tempo de retenção, que foi reprodutível sob as mesmas condições, e quantitativos, após correções apropriadas da linha de base, utilizando a altura do pico.

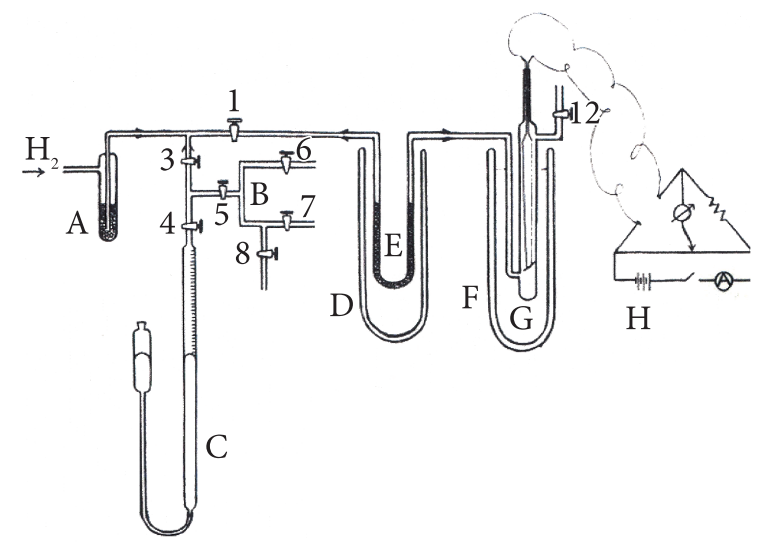

Figura 2 Equipamento utilizado por Cremer, Prior e Müller. A: sorvente para secar o hidrogênio (fase móvel); B: sistema para injeção da amostra; torneira 8 foi ligada a uma bomba de vácuo; torneira 4 permite medir e, depois, empurrar a amostra com mercúrio contido no tubo C; D e F: frascos termostatisados; $\mathrm{E}$ : coluna recheada com fase estacionária sólida; $\mathrm{G}$ : catarômetro; $\mathrm{H}$ : ponte de Wheatstone com galvanômetro no centro (modificado de Wintermeyer ${ }^{[6]}$ ).
O trabalho de Prior foi estendido por outro aluno de pós-graduação, Roland Müller, que utilizou o mesmo equipamento e realizou várias separações com uma coluna recheada com sílica. Com esta fase estacionária, a separação de acetileno e etileno foi atingida (Figura 4). Na sua tese ${ }^{[9]}$, Müller também comprovou a previsão de aplicações quantitativas (Figura 5), com linearidade entre 0,5 e $10 \mathrm{mg}$ das substâncias.

As condições na Áustria, após o fim da segunda guerra mundial, eram péssimas e viagens para apresentar trabalhos em congressos eram altamente restritas. Assim, os resultados do

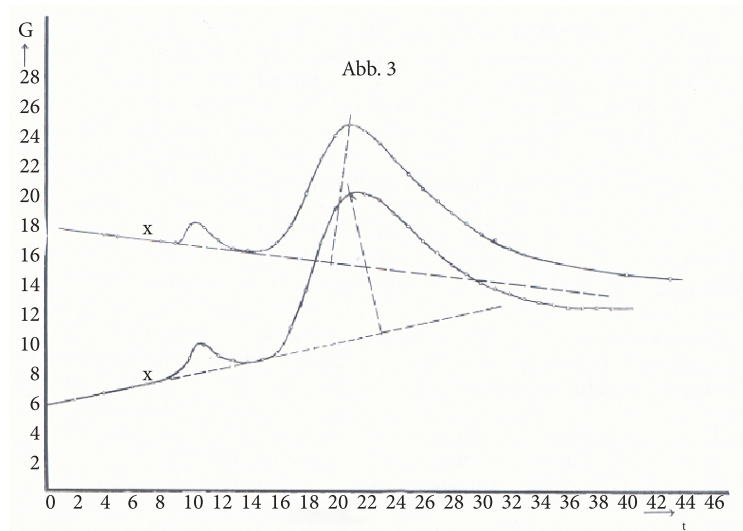

Figura 3 Primeiro cromatograma analítico adquirido com o sistema cromatográfico de Cremer e Prior, publicado na tese de Prior. A fase móvel foi hidrogênio e a fase estacionária foi carvão ativado. Os picos foram, respectivamente, ar e dióxido de carbono (modificado de E. Cremer ${ }^{[7]}$ ).

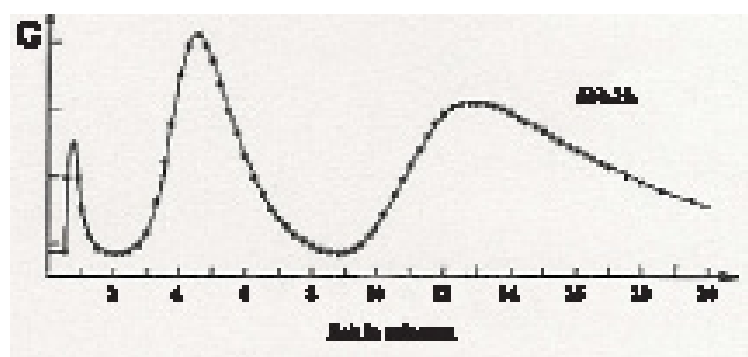

Figura 4 Separação de etileno e acetileno com fase estacionária de sílica, realizada por Müller. O primeiro (pequeno) pico foi ar. A fase móvel foi hidrogênio (modificado de E. Cremer ${ }^{[7]}$ ). 


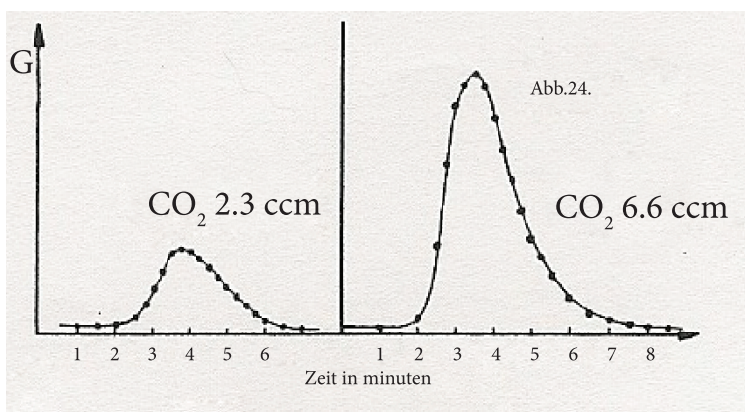

Figura 5 Cromatogramas ilustrando as diferentes alturas de pico (e áreas do pico) com a injeção de diferentes quantidades de dióxido de carbono (modificado de E. Cremer ${ }^{[7]}$ ).

trabalho de Prior foram apresentados em Linz em 1947 e publicados em 1951 ${ }^{[10]}$. Um trabalho com os resultados de Müller foi também publicado no mesmo ano ${ }^{[11]}$. Por outro lado, poucos pesquisadores demonstraram interesse em separações na fase gasosa. Este fato foi comprovado pela falta de interesse demostrada quando, em 1952, Cremer apresentou seu equipamento na exibição ACHEMA em Frankfurt am Main, Alemanha.

A Profa. Erika Cremer continuou na Universidade de Innsbruck após o fim da guerra. Quando as condições melhoraram na universidade, ela expandiu suas linhas de pesquisa para incluir a cromatografia gás-líquido, entretanto continuou com a cromatografia gás-sólido para determinações quali e quantitativas de gases e compostos voláteis e como ferramenta para estudos das propriedades de diversos gases. Cremer foi promovida a professora titular em 1951 e recebeu o título de professora emérita em 1965 na Universidade de Innsbruck. As suas contribuições à cromatografia gás-sólido e à cromatografia em geral foram reconhecidas com vários prê- mios, incluindo o prêmio "Erwin Schrödinger" da Academia de Ciências Austríaca em 1970 e a primeira medalha "M.S. Twett" em 1974.

\section{Referências}

1 Collins CH. Precursores da cromatografia gás-sólido. Scientia Chromatographica 2011; 3(4):281-288.

2 Hesse G. Adsorptionmethoden im chemischen Laboratorium, mit besonderer Berrücksichtigung der chromatographischen Adsorptionsanalyse (TswettAnalyse). Berlin: W. De Gruyter \& Co.; 1943.

3 Kunte, A. Adsorption und Desorption von Acetylen uns Äthylen an aktiver Kohle. Diplomarbeit: Universität Insbruck; 1944.

4 Cremer E. Über die Wanderrungsgeschwindigbut der Zonen bei der chromatographischen Analyse. Chromatographia 1976; 9:363-6. http://dx.doi. org/10.1007/BF02330384

5 Cremer E. How we started to work in gas adsorption chromatography. Chromatographia 1976; 9: 364.

6 Wintermeyer U. Historical review. In: Unger KK, editor. Packings and Stationary Phases in Chromatographic Techniques. New York: Marcel Dekker; 1990. cap. 1.

7 E. Cremer In: Ettre LS, Zlatkis A, editors. 75 years of chromatography - a historical dialogue. Amsterdam: Elsevier, 1979. p. 20-30.

8 Prior F. Über die Bestimmung der Adsorptionswärmen von Gasen und Dämpfen unter Answendung der chromatographischen Methode auf der Gasphase [thesis]. Innsbruck: University of Innsbruck; 1947.

9 Müller R. Anwendung der chromatographischen Methode zur Trennung und Bestimmung kleinsten Gasengen [thesis]. Innsbruck: University of Innsbruck; 1950.

10 Cremer E, Prior F. Anwendung der chromatographischen Methode zur Trennung von Gasen und der Bestimmung von Adsorptionsenergien. Zeitschrift für Elektrochemie und angewandte physikische Chemie 1951; 55:66-9.

11 Cremer E, Müller R. Trennung und Bestimmung von Substanzen durch Chromatographie in der Gasphase. Zeitschrift für Elektrochemie und angewandte physikische Chemie 1951; 55:217-20. 